\title{
Archimboldi: El agujero negro de 2666
} Archimboldi: The black hole in 2666

\author{
Felipe Ríos \\ Benemérita Universidad Autónoma de Puebla, México \\ feliperios.ffyl@gmail.com
}

\section{Resumen}

Este ensayo busca demostrar una hipótesis: que en la obra de Roberto Bolaño el tiempo será asumido como un viaje hacia el caos y la percepción de "desfases" en la estructura cronológica. Dicho enfoque se aplicará concretamente a 2666, la novela donde Bolaño expuso su mayor preocupación por la cuestión temporal, y en especial a "La parte de Archimboldi”, donde se evidencia que el escritor alemán no sólo actuaría como un personaje que, debido al hechizo de sus novelas, provoca su ulterior persecución, sino que opera como un verdadero "agujero negro", capaz de fagocitar toda circunstancia estética $\mathrm{y}$ vivencial que gire a su alrededor.

Palabras clave: Tiempo, 2666, Roberto Bolaño, agujero negro.

\section{Abstract}

This essay attempts to prove the hypothesis that, in Roberto Bolaño's work, time will be assumed as a trip to chaos and the perception of "time lags" within the chronological structure. This approach will be applied, concretely, to 2666, where Bolaño presented his greatest concern about the subject of time, and more specifically to "The Part of Archimboldi", where it is evident that the German writer would not only act as a character who, because of his novels' charm, causes his latter persecution, but also would act as a true "black hole", capable of gobbling up all the aesthetical and existential circumstances that surround him.

Keywords: Time, 2666, Roberto Bolaño, Black Hole. 
Tanto en su obra de ficción como en sus textos críticos, son varios los momentos en los que el escritor chileno Roberto Bolaño (1953-2003) asume la noción de tiempo en la literatura como algo más que el desensamblaje del mythos aristotélico (la linealidad o causalidad de eventos) o la refractación en el espacio semiótico de una categoría fenoménica (el reconocido cronotopo bajtiniano). Mientras el ex drogadicto del cuento "Playa", tendido sobre la arena y observando a los bañistas, se dice a sí mismo "que el tiempo tal vez no existía tal como yo creía que existía, reflexionaba sobre el tiempo mientras la lejanía del sol alargaba las sombras de los edificios, y luego me iba a casa y me daba una ducha y miraba mi espalda roja [...]" (El secreto del mal 126), el narrador del cuento "Dentista" lo intuirá de otro modo: “[...] tal vez ahora exagero, mi memoria exagera, tal vez no exagero, tal vez entonces se abrió el agujero real [...]" (Putas asesinas 188).

Este trabajo afirma que en la obra de Bolaño el tiempo será asumido como un viaje hacia el caos y la percepción de "desfases" en la estructura cronológica. Si bien en trabajos anteriores se habían realizado planteamientos críticos similares ${ }^{1}$, dichos enfoques se amplían aquí al asumir como objeto de estudio "La parte de Archimboldi”, de 2666, pues nos parece que es en esta obra donde Bolaño expuso su mayor preocupación por estas cuestiones, hasta llevarlas a sus expresiones más complejas. De este modo, y leyendo detenidamente la última parte de esa novela, hay buenas razones para suponer que la presencia de Hans Reiter, el futuro Benno von Archimboldi, resulta tan inquietante como la de Auxilio Lacouture en Amuleto, para entender que el tiempo y el espacio varían frente a la consideración de determinados agentes ${ }^{2}$.

Incluso, para algunos de los primeros estudiosos serios de la novela póstuma de Bolaño, el título mismo de la novela alude al propósito esencial de desestabilizar cualquier lógica temporal y armonía estructural de sucesos. En su ensayo "2666: La autoría en el tiempo del límite", Peter Elmore dirá: "El año 2000 y la cifra del Anticristo se funden en el título, que indica el encuentro (inestable, extraño) de la crónica de lo contemporáneo con el registro visionario" (261), y Patricia Poblete Alday menciona que “'2666” ya no es (únicamente) una fecha, sino que remite a un imaginario específico, el apocalíptico [...]; divide la cifra en dos: 2 y 666” (26-27). La presencia de Archimboldi no sólo provocará una discusión casi espontánea acerca de la percepción del tiempo y sus pormenores entre quienes lo rodean, sino que llegará un momento en el cual se perciba que el tiempo transcurre en velocidades dispares o bien que no transcurre para nada.

1 Vid. Felipe A. Ríos Baeza, "Arturo Belano: El viajero en el tiempo" (2010); y Felipe A. Ríos Baeza, "Las jornadas del caos: La noción de tiempo en Los detectives salvajes, de Roberto Bolaño" (2012).

2 “"[...] se rompió el rombo en el espacio de la desesperación conjetural, subieron las imágenes del fondo del lago, sin que nada ni nadie pudiera evitarlo emergieron las imágenes de ese pobre lago al que no alumbran ni el sol ni la luna, se plegó y desplegó el tiempo como un sueño [...]. [M] e puse a pensar en mi pasado como si pensara en mi presente, en mi futuro y en mi pasado, todo revuelto y adormilado en un solo huevo tibio, un enorme huevo de no sé qué pájaro interior (¿un arqueopterix?) cobijado en un nido de escombros humeantes" (Amuleto 35), puede leerse en dicha novela. 
Como si de una autoexégesis se tratara, Bolaño se complace en narrar que Benno von Archimboldi tuvo, al comienzo, muchas dificultades para publicar. Después de probar suerte en varias editoriales de Colonia con su novela Lüdicke, sólo le quedará golpear la puerta de El Consejero, una pequeña editorial que escasamente publica poesía y novela. El encargado, Michael Bittner, había sido entrenado como paracaidista militar, aunque aún no había tenido la suerte de saltar en paracaídas. El suceso más relevante en la vida de Mickey había sido experimentar un "bombardeo en alfombra" por parte del ejército norteamericano. Como todo ex soldado, Bittner se lo cuenta a Reiter con un orgullo enaltecido. Pero en los espacios en blanco del discurso del editor, el futuro Archimboldi intuye que dividir el tiempo en sucesos determinantes, en eventos radicales, es una mera arbitrariedad. El tiempo es "otra cosa", donde "nada" y a su vez "todo" ocurre caóticamente:

- No sé si me he explicado con claridad, Benno -dijo mirando a Archimboldi fijamente a los ojos.

- Se ha explicado usted con claridad meridiana, Mickey -dijo Archimboldi al tiempo que pensaba que el tipo en cuestión no sólo era pesado sino también ridículo, con esa ridiculez que sólo tienen los histriones y los pobres diablos convencidos de haber participado en un momento determinante de la historia, cuando es bien sabido, pensó Archimboldi, que la historia, que es una puta sencilla, no tiene momentos determinantes sino que es una proliferación de instantes, de brevedades que compiten entre sí en monstruosidad (2666 993).

La referencia es clara. En una competencia a brazo partido por ocupar un sitial en la historia (otra construcción basada en la estructura lógica aristotélica, y también en el céntrico poder político-militar), los eventos chocan, se unen, se repelen, se evaporan. Dice Archimboldi que los instantes "proliferan", es decir, se reproducen con abundancia y sin control simétrico alguno.

Por ende, ¿cómo entender el trabajo temporal en 2666, tomando en cuenta la súbita aparición de personajes y situaciones que luego se desvanecen sin más en la narración? ¿Cómo entender los encuentros, o los chispazos de encuentros, que irá teniendo Archimboldi, desde su padre cojo y su madre tuerta hasta Alexander fürst Pückler, pariente del creador del helado que lleva su nombre?

Aunque de forma más atenuada, Archimboldi actuará como el viejo escritor Morelli de los "capítulos prescindibles" en Rayuela, de Julio Cortázar. Es decir, como un "orientador" o "propiciador" de las claves de lectura de la globalidad de 2666. Es interesante llevar a cabo este estudio, pues existen algunos momentos relevantes en los que la discusión o encarnación de una temporalidad, como se ha entendido aquí, posibilitará un análisis diverso al clásico ajuste que se ha pretendido hacer de la obra con las leyes de la causalidad. 


\section{Pausa y música: Dos dimensiones archimboldianas}

Habitualmente se conoce como "agujero negro" a un "objeto contraído por gravitación", es decir, un objeto astrofísico que contiene una ingente cantidad de masa en un volumen muy reducido. En este contexto la fuerza gravitacional es tan fuerte que ni siquiera la luz tiene suficiente energía para escapar. Literalmente, los "agujeros negros" se "tragan" los planetas, las estrellas, la basura cósmica y todo aquello que circule en su órbita. Stephen Hawking reconoce a la "frontera" de esos "agujeros negros" como "horizonte de sucesos y coincide con los caminos de los rayos luminosos que están justo a punto de escapar del agujero negro, pero no lo consiguen [...]. Cualquier cosa o persona que cae a través del horizonte de sucesos pronto alcanzará la región infinita y el final del tiempo" (121-125).

En Los detectives salvajes, el diario de Juan García Madero presentaba, al inicio de la tercera parte, un desfase temporal que abría la peligrosa posibilidad de estar delante de una novela - "agujero negro", la cual fagocitaba todas las circunstancias, personajes y espacios a su paso:

Hoy me di cuenta de que todo lo que escribí ayer en realidad lo escribí hoy: todo lo del treintaiuno de diciembre lo escribí el uno de enero, es decir hoy, y lo que escribí el treinta de diciembre lo escribí el treintaiuno, es decir ayer. Lo que escribo hoy en realidad lo escribo mañana, que para mí será hoy y ayer, y también de alguna manera mañana: un día invisible (557, la cursiva es mía).

Ese "día invisible" había conseguido introducir, en el paso del 31 de diciembre de 1975 al 1 de enero de 1976, de manera compleja y farragosa veinte años (1976-1996) en la vida de Belano y Lima. Este asunto es llevado al extremo en "La parte de Archimboldi", pues el "agujero negro" no será representado por algo "invisible", como un día que desaparece en un diario de vida, sino por un personaje. Archimboldi no sólo habitará en un agujero negro: será ese agujero negro. Resulta sintomático que la mera presencia de Archimboldi provoque, en cualquiera de los entornos en los que se encuentra, alteraciones determinantes. En algunas ocasiones aparecen coloquialmente mencionadas, y en otras se dramatizan como experiencias radicales, donde Archimboldi será el componente temporal que altere las estructuras de cosmovisión de quienes lo rodean ${ }^{3}$.

3 Situación parecida ocurrirá con el personaje de El Quemado, en El Tercer Reich, quien provoca una extrañeza en la percepción del entorno del narrador y protagonista, Udo Berger: "Después de dejar el patín el Quemado dijo que debería nadar un rato. -¿Por qué?

-El sol te está fundiendo los plomos -aseguró.

Me reí y lo invité a venir al mar conmigo.

Nadamos un tramo ocupados sólo en avanzar, hasta salir de la primera franja de bañistas. Entonces nos pusimos de cara a la playa: desde allí, junto al Quemado, la playa y la gente apiñada parecían distintas [...]. Con premeditada brusquedad desperté a Ingeborg y nos marchamos" (El Tercer Reich 83). 
Antes de redactar El jardín, D’Ansorval o La máscara de cuero, el joven Hans Reiter solía compartir tragos y cafés con algunos amigos. Hugo Halder, sobrino de un barón prusiano y dueño de una exquisita biblioteca, al que el padre de Reiter y Reiter mismo sirvieron alguna vez, y Noburo Nisamata, secretario del encargado de asuntos agrícolas de la legación del Japón en Alemania, se contaban entre ellos. Reiter, Halder y Nisamata (al que apodaban Nisa) formaban un trío variopinto, que disfrutaba de asistir a cabarets y a cafés intelectuales. No obstante, cuando el ambiente parecía distenderse en pláticas amenas y cotidianas, de pronto un manto de silencio terminaba por ensombrecer las escenas. Se sospecha que Reiter, por el sólo hecho de estar allí, es quien modifica la escena:

En ocasiones, sin embargo, sentado en las terrazas o alrededor de una oscura mesa de cabaret, el trío se instalaba sin que viniera a cuento en un silencio obstinado. Parecían petrificarse de repente, olvidar el tiempo y volverse del todo hacia dentro, como si dejaran de lado el abismo de la vida diaria, el abismo de la gente, el abismo de la conversación y decidieran asomarse a una región como lacustre, una región romántica tardía, en donde las fronteras se cronometraban de crepúsculo a crepúsculo, diez, quince, veinte minutos que duraban una eternidad, como los minutos de los condenados a muerte, como los minutos de las parturientas condenadas a muerte que comprenden que más tiempo no es más eternidad y que sin embargo desean con toda su alma más tiempo, y esos vagidos eran los pájaros que cruzaban de vez en cuando y con cuánta serenidad el doble paisaje lacustre, como excrecencias lujosas o como latidos del corazón. Después, como es natural, salían acalambrados del silencio y volvían a hablar de inventos, de mujeres, de filología finlandesa, de la construcción de carreteras en la geografía del Reich (2666 828-829, la cursiva es mía).

La descripción parece indicar el ingreso de los personajes a otra dimensión espaciotemporal, donde la estructura ordinaria del tiempo civil queda anulada y el reloj que marca diez, quince, veinte minutos acaba defraudando como medida de exactitud. "Más tiempo no es más eternidad", señala el narrador, pues el tiempo por sí solo carece de significado si se neutraliza o anula la participación del sujeto como variable en el fenómeno. Mientras Halder y Nisa parecen pasmarse ante el silencio abrupto (Halder y Nisa se ubicarían, como García Madero, en el "horizonte de sucesos", en los bordes del agujero negro), Reiter es consciente de que esas categorías no surgen a priori del contacto con el mundo, sino que se mueven y alcanzan significado con él.

De esta manera, el tiempo termina siendo succionado con el movimiento final de Reiter en "La parte de Archimboldi": se marcha a México, el sitio donde, como se apunta en "La parte de Fate", en Los detectives salvajes y en algunas entrevistas de Bolaño, todo parece acontecer únicamente para diseminarse; el sitio donde está el "secreto del mundo" que, más adelante, se conocerá también como el "secreto del mal". 
Otra circunstancia evidente de la alteración en la temporalidad provocada por la presencia de Archimboldi acaece durante la visita en casa de una vieja amiga de Hugo Halder, Grete von Joachimsthaler. Se trata de una dama siempre dispuesta a abrir las puertas de su hogar a todo tipo de tertulias. En ellas se interpretan piezas musicales, se habla de libros y se debate en torno a la vida cultural alemana. Sin embargo, no es sino hasta la llegada de Reiter que lo que comienza a preocuparles verdaderamente a los asistentes es el tiempo. Especialmente, un tiempo vinculado a sus propias disciplinas artísticas:

A casa de Grete solían acudir músicos, incluso un director de orquesta que afirmaba que la música era la cuarta dimensión y a quien Halder estimaba mucho [...]. La cuarta dimensión, decía, contiene a las tres dimensiones y les adjudica, de paso, su valor real, es decir anula la dictadura de las tres dimensiones, y anula, por lo tanto, el mundo tridimensional que conocemos y en el que vivimos. La cuarta dimensión, decía, es la riqueza absoluta de los sentidos y del Espíritu (con mayúscula), es el ojo (con mayúscula), es decir el Ojo, que se abre y anula los ojos, que comparados con el Ojo son apenas unos pobres orificios de fango, fijos en la contemplación o en la ecuación nacimiento-aprendizaje-trabajo-muerte, mientras el Ojo se remonta por el río de la filosofía, por el río de la existencia, por el río (rápido) del destino (829-830).

Es elocuente que a partir de una disciplina como la música pueda intuirse el centelleo de una dimensión en la cual los sucesos se percibirán como "proliferación" de instantes, otorgando mayor complejidad al oficio que se ejecuta. En este caso, la música puede generarse teniendo como base material doce notas (del do al si, deteniéndose en sus intermedios tonales); es decir, una potencial estructura de secuencias temporales muy marcadas. El reloj, de las 12 a la 1 y sus fracciones mediales, es también una estructura potencial. Si la música ha empleado variaciones de ese sistema de doce notas para generar corrientes que abrirían la percepción hacia otra dimensión (como en el caso de la música dodecafónica o la música concreta), ¿por qué no permitir que el tiempo que se percibe psicológicamente derive su trayectoria hacia un tiempo relativo, abierto?

Continúa el director de orquesta:

La cuarta dimensión, decía, sólo era expresable mediante la música. Bach, Mozart, Beethoven [...]. Según el director, la vida -tal cual- en la cuarta dimensión era de una riqueza inimaginable, etc., etc., pero lo verdaderamente importante era la distancia con que uno, inmerso en esa armonía, podía contemplar los humanos asuntos, con ecuanimidad, en una palabra, sin losas artificiales que oprimieran el espíritu entregado al trabajo y a la creación, a la única verdad trascendente de la vida, aquella verdad que crea más vida y luego más vida y más vida, un caudal inagotable de vida y alegría y luminosidad (830-831). 
Aquí la cita de Bolaño entraría en estrecho contacto con algunos de los planteamientos del filósofo alemán Peter Slöterdijk. En varios momentos de esos volúmenes que llevan por título general Esferas, Slöterdijk asegura que para poder experimentar la esencia y la existencia en el mundo, se debe necesariamente haber estado "ausente" con anterioridad, lo que explicaría su enigmática definición del hombre como "el metafísico animal de la ausencia". De esta forma, la experiencia de ser y estar en el mundo, un mundo sensorial, se apreciaría como un "regreso". Sin embargo, el mundo contemporáneo no legitima ninguna posibilidad de "ausencia", a pesar de que por todos los "altavoces", por todos los registros "musicales" posibles, se estaría anunciando el "olvido del ser".

La esencialidad de la música estaría remitiendo a que la dimensión de la vida humana perceptible no sólo es reducida, sino que se empobrece cada vez más. Es un requisito acercase a este tipo de lenguajes no sólo para "ausentarse" y luego volver a "presentarse" en el mundo, sino para comprender que la simplificación del tiempo a una dimensión de principio-medio-final es falaz. "Escuchar música significa siempre ser-en-la-música, estar en ella, y en ese sentido tenía razón Thomas Mann cuando decía que la música era un territorio demoníaco: quien escucha, en efecto, está poseído actualmente por el sonido" (Slöterdijk 275), puede leerse en el ensayo "Excurso 2: Nobjetos e irrelaciones. Para una revisión de la doctrina psicoanalítica de las fases". Y en "El estadio-sirenas. De la primera alianza sonosférica", advierte: "Hay una música extraña en el mundo, de la que han de precaverse precisamente los más capaces: pues esos sonidos, como dan a entender los mitólogos, conducen al oyente no hacia sí, hacia su propio bien, sino a la muerte lejos de la patria” (Slöterdijk 438).

¿Por qué la música?, ¿qué hay en la música que parece incorporar al sujeto a estadios perceptivos alterados o más avezados? El filósofo Adolfo Vásquez Rocca, uno de los más atentos estudiosos de la obra de Slöterdijk en América Latina, lleva a cabo una crítica, en su artículo "Música y filosofía. Registros polifónicos: de Johnny Cage a Peter Slöterdijk", acerca de una propiedad de la música que se condeciría con la captación fenomenológica de un mundo más allá de las limitantes conceptuales de "tiempo" y "espacio". Según Vásquez Rocca, la música no sería un arte dirigido al oído humano:

Se afirma generalmente que la música "se dirige al oído". Pero esto lo hace, en cierto modo, nada más en la medida en que el oído, como los demás sentidos, es un órgano e instrumento perceptivo de lo intelectual. Pero en realidad, y esto debe ser destacado, hay música que no contó nunca con ser oída; es más, que excluye la audición. Así ocurre con un canon a seis voces de Johann Sebastian Bach, escrito sobre una idea temática de Friedrich el grande. Se trata de una composición que no fue escrita ni para la voz humana ni para la de ningún instrumento, concebida al margen de toda realización sensorial, y que de todos modos es música, tomando la música como una pura abstracción. Quién sabe, decía Kretzschmar, si el deseo profundo de la Música es de no ser oída, ni siquiera 
vista o tocada, sino percibida y contemplada, de ser ello posible, en un más allá de los sentidos y del alma misma ("Música y filosofía" 2006).

Tal y como se pregunta Slöterdijk: ¿dónde estamos cuando escuchamos música? En la tertulia en casa de Grete, alguien propone que se examine el asunto no desde una cuarta dimensión de la realidad, sino desde una quinta y hasta de una décima dimensión. Es decir, que se trascienda el carácter temporal, logrando con ello la "ausencia" propuesta. Lo importante para este análisis literario es dar cuenta de que aunque se puedan explorar otras dimensiones desde el punto de vista musical o cuántico, será la sensibilidad y los valores apreciativos de lo artístico los que radicalmente cambiarán:

\begin{abstract}
¿Qué pensarían los que vivían en la décima dimensión, es decir los que percibían diez dimensiones, de la música, por ejemplo? ¿Qué era para ellos Beethoven? ¿Qué era para ellos Mozart? ¿Qué ella para ellos Bach? Probablemente, se contestó a sí mismo el joven Reiter, sólo ruido, ruido como de hojas arrugadas, ruido como de libros quemados (2666 831).
\end{abstract}

De esta manera, Archimboldi no sólo provoca que espontáneamente los tertulianos vinculen sus oficios con el tema del tiempo, sino que esa conversación en su juventud calará hondo para su propio programa escritural. Hacia esa zona, donde "los sentidos y el alma misma” deben abrirse para habitar en una percepción más elevada es donde Archimboldi apuntalará todo su estimulante sistema de creación. Así, la "cuarta dimensión" se vuelve el eje de su poética: al comprender que puede accederse a una cuarta, quinta o décima dimensión de la realidad con auxilio de la audición musical, Reiter intuye que, una vez allí, el sonido de Bach, el más eximio de los compositores, no será más que un ruido de hojas de libros destruidas. Su propósito, desde la publicación de su primera novela, será explorar literariamente ese territorio violentado intrínsecamente por el elemento del tiempo.

Es otro modo de comprender a Archimboldi como un "agujero negro": cualquier manifestación, persona o conversación que se encuentre orbitando en su "horizonte de sucesos" será fagocitado hacia su negro interior, donde todo es plausible de volverse literatura. De esta manera, sus críticos europeos Pelletier, Norton, Morini y Espinoza ya no podrán seguir siendo vistos como "autoridades" en la interpretación de la obra archimboldiana, y su aportación se verá reducida únicamente al punto de vista narrativo. Quienes mayormente propondrán un alcance multidimensional al escritor alemán serán Amalfitano y Fate, a pesar de acercarse oblicuamente a los libros de Archimboldi o de ni siquiera haberlos leído (como el "Canon a seis voces", compuesto por Bach para no poder ser interpretado ni escuchado).

Oscar Fate, ya desentendido del propósito inicial que lo guió a la frontera con México (reportear la pelea de boxeo), comienza a decodificar la urdimbre macabra de los asesinatos en Santa Teresa junto con Guadalupe Roncal (reportera encargada 
de cubrir las declaraciones del presunto asesino y sobrino de Archimboldi, Klaus Haas) y la hija de Óscar Amalfitano, Rosa. En un viaje en carretera, se produce una intuición que vincularía la fuerte presencia de un "albino" con la explicación definitiva, imposible de hallar en esta dimensión, acerca de la ignominia criminal: "Nadie presta atención a estos asesinatos, pero en ellos se esconde el secreto del mundo. Lo dijo Guadalupe o lo dijo Rosa. La carretera era similar a un río. Lo dijo el presunto asesino, pensó Fate. El jodido albino que apareció junto con la nube negra" (439).

Si bien Joaquín Manzi señalaba, a propósito de Los detectives salvajes, que "el secreto de la vida no está en los libros" (165), en 2666 el secreto del mundo sí estaría inserto, superando una inicial dimensión perceptiva de la realidad, en los libros de Archimboldi. Pero tal como ocurría con la poesía realvisceralista, la novelística del alemán también se suprime del texto: en una elipsis funcional, no es revelada al lector real. ¿Cuál es, entonces, ese secreto del mundo que se mantiene celosamente oculto, en páginas que no se muestran? Se presume que será un colega de Oscar Fate, el también periodista Joe A. Kelso, quien tenga el privilegio de conocer la revelación final. Una voz misteriosa, que luego se identifica como Sacha Pinsky, le da cita a Kelso en un puente de París. Juntos se meten a un cafetín, y antes de que Pinsky le transmita la importantísima información que desea darle, Kelso lo escudriña con detención. Todo esto ocurre en un cuento que, inquietantemente, se llama "El secreto del mal" y que, más inquietante aún, queda inconcluso "porque este tipo de historias no tienen un final" (El secreto del mal 23). Así, en una realidad de cuatro o más dimensiones, siempre habrá tiempo que perder.

\section{Pasatiempos de cosmología}

$\mathrm{Al}$ igual que su sobrino Klaus Haas, Hans Reiter no parece comportarse como un ser que habite el mismo mundo material que conocen sus lectores y la gente que lo rodea. Mientras Haas es descrito por varios personajes que deambulan por Santa Teresa como un gigante amenazador (es decir, una presencia que distorsiona un esquema socialmente armónico), Archimboldi será definido con trazos más gruesos, más difusos, aunque manteniendo la constante de su presencia como perturbación violenta de la temporalidad.

Si la cercanía del futuro escritor provocaba en sus amigos el acceso a una cuarta dimensión de la realidad por la vía de una percepción temporal huidiza o detenida, para Ingeborg, su amiga y amante, estar en el "horizonte de sucesos" de Archimboldi provocará una súbita conversación referida a ese espacio en el cual confluyen caóticamente cuerpos celestes que dan cuenta de las distintas fases en la "historia del tiempo" y zonas caracterizadas por una inquietante propiedad de fagocitación.

En una noche despejada, mientras caminan juntos por una montaña, Ingeborg se detiene un momento e interpela a Reiter. Le pregunta si tiene idea dónde están. 
Reiter responde vagamente, haciendo alusión a lo que está a sus pies y no sobre su cabeza. "Estamos en la montaña", replica Ingeborg, "pero también estamos en un lugar rodeado de pasado. Todas esas estrellas [...], ¿es posible que no lo comprendas, tú que eres tan listo?” (2666 1040). Aquí Archimboldi vuelve a orientar de forma muy funcional, como ocurría con Bach y el acceso a otras dimensiones a partir de la música, el debate hacia el fenómeno literario, ese "espacio" que, como mundo posible y fictivo, violenta toda estructura lógica y cronológica de ese otro mundo posible llamado "realidad":

- Toda esa luz está muerta -dijo Ingeborg-. Toda esa luz fue emitida hace miles y millones de años. Es el pasado, ¿̨lo entiendes? Cuando la luz de esas estrellas fue emitida nosotros no existíamos, ni existía vida en la tierra, ni siquiera la tierra existía. Esa luz fue emitida hace mucho tiempo, ¿lo entiendes?, es el pasado, estamos rodeados por el pasado, lo que ya no existe o sólo existe en el recuerdo o en las conjeturas ahora está allí, encima de nosotros, iluminando las montañas y la nieve y no podemos hacer nada para evitarlo.

- Un libro viejo también es el pasado -dijo Archimboldi-, un libro escrito y publicado en 1789 es el pasado, su autor ya no existe, tampoco existe su impresor ni sus primeros lectores ni la época en la que el libro fue escrito, pero el libro, la primera edición de ese libro, aún está aquí. Como las pirámides de los aztecas -dijo Archimboldi.

- Odio las primeras ediciones y las pirámides y también odio a esos aztecas sanguinarios -dijo Ingeborg-. Pero la luz de las estrellas me marea. Me dan ganas de llorar-dijo Ingeborg con los ojos húmedos de locura (1041).

La contemplación de una realidad que para poder comprenderse obliga al observador a dotarse de un marco de entendimiento "más allá de lo evidente" (la actitud de Ingeborg viendo las estrellas, es decir, viendo el sitio donde todo ha comenzado y donde probablemente todo acabe), invariablemente marea. En ese vahído que experimenta Ingeborg, Archimboldi intenta aterrizar la particular noción de "pasado" de su amante (de cosas inmutables, anteriores e incluso superiores a ellos) al fenómeno hermenéutico del libro. Se trata de una idea muy borgesiana de intentar intuir un tiempo caracterizado por su movilidad y su exuberancia, trascendente a cualquier circunstancia humana existente alrededor del libro. Decir "libro viejo" es un equivalente del anterior "libro quemado" comentado en las tertulias de Grete von Joachimsthaler, donde su presencia sólo explica que los demás elementos que alguna vez estuvieron a su alrededor han desaparecido en sus fauces.

En esta conversación entre Ingeborg y Archimboldi, la estrecha relación entre un espacio (el universo) donde el tiempo parece "estacionario" (que no estático) y la enigmática permanencia del libro más allá de la extinción de la humanidad resulta casi un homenaje soterrado a uno de sus escritores preferidos: "El universo (que otros llaman la Biblioteca) se compone de un número indefinido, y tal vez infinito, 
de galerías hexagonales, con vastos pozos de ventilación en el medio, cercados por barandas bajísimas" (Borges, "La bibioteca de Babel" 111), puede leerse en "La biblioteca de Babel". Es decir, a pesar de la estructura, a pesar de la organización, lo que allí se intuye es el desmantelamiento. Aunque en un comienzo Borges dude acerca de la infinitud de la Biblioteca, pronto intuye que la combinación de símbolos ortográficos con los que se generan los libros es vastísima, pero finita y coincidente. En ese sentido, el universo también tendría un tamaño finito, también sería plausible de medirse y organizarse en galerías hexagonales, pero esa sensación de infinitud (la sensación de Ingeborg de que todo "ya ha ocurrido" tiempo atrás) sería dada no por el universo en sí, sino por la problemática de sus límites o fronteras.

Otra vez un margen que disemina (y se disemina) entra en juego. Sobre lo mismo, Stephen Hawking señala que "quizás el tiempo y el espacio juntos formen una superficie que sea finita en tamaño, pero que no tenga ninguna frontera ni ningún borde" (Historia del tiempo 181). Aunque el físico se apure en señalar que este planteamiento es sólo una "propuesta" que no podrá sostenerse científicamente hasta que surja una teoría que combine satisfactoriamente la relatividad general con la mecánica cuántica, sí es intuitivo al afirmar que sin los bordes, con plena apertura de los márgenes, cualquier historia o trayectoria que siguiera el universo (contenida en libros que pudieran escribirse, envejecer o quemarse) entraría en el plano de lo probable: "Todo esto podría sugerir que el llamado tiempo imaginario es realmente el tiempo real, y que lo que nosotros llamamos tiempo real es solamente una quimera" (184). A fin de cuentas, otro modo de decir que al literaturizar los acontecimientos se accede a una dimensión donde el tiempo deja de ser un concepto absoluto y se relativiza, incluso teniendo el fulgor de las estrellas como un indicador del "pasado".

Archimboldi habla de un libro escrito y publicado en 1789 , que tiene la facultad de "permanecer", de dar cuenta de la finitud del universo pero de la infinitud del tiempo. ¿Cuál pudiera ser ese libro que actúa casi como un grimorio, un texto caracterizado por su trascendentalidad? En el año de la revolución francesa se publican al menos tres tratados importantes: Historia natural de Selbourne, del naturalista y ornitólogo Gilbert White; el Tratado elemental de Química, de Antoine-Laurent de Lavoisier; y el Ensayo sobre la ley de la población, de Thomas R. Malthus. Es el año, también, en el cual Jeremy Bentham publica Introducción a los principios de moral $y$ legislación y Emmanuel Joseph Sieyès hace lo propio con ¿Qué es el tercer estado? No obstante, Archimboldi inmediatamente "descentraliza" la visión eurocéntrica y se refiere al continente mesoamericano. También en 1789, el sacerdote jesuita guanajuatense Andrés de Guevara y Basoazábal publicó un tratado cuando menos extravagante: Pasatiempos de cosmología o entretenimientos familiares acerca de la disposición del universo, obra en la que se hace un repaso, en un tono decididamente hilarante, de las contribuciones más importantes de las escuelas astronómicas que describieron el universo. A partir de la aceptación del giro copernicano, Guevara y 
Bosazábal parece reverenciar, también, la visión cosmogónica sagrada de las civilizaciones prehispánicas mexicanas ${ }^{4}$.

Visto así, este pasaje adquiere también reminiscencias ceremoniales debido a esa mención, aparentemente arbitraria, a las pirámides aztecas. En su libro El estado azteca, la antropóloga María Rodríguez Shadow vincula estrechamente las prácticas bélicas y rituales de los aztecas con la mantención del orden en el universo: "Las deidades exigían, según la cosmogonía oficial, constante obediencia, sumisión y el uso de la guerra como un mecanismo para asegurar, mediante el rito sacrificial, la supervivencia del universo" (133-134). Incluso la arquitectura de los basamentos piramidales mesoamericanos eran funcionales a los rituales de sacrificio (y parecen aludir al dibujo del "agujero negro"). En lo alto de la pirámide se encontraba el altar de muerte, donde quien había sido escogido como ofrenda a la divinidad subía acompañado de cinco sacerdotes. Cuatro sostenían cada una de sus extremidades y el sumo sacerdote (el más hábil, el más rápido) extraía el corazón palpitante del sacrificado, lo elevaba hacia el sol (la estrella mayor, la organizadora del sistema planteario) y luego lo arrojaba al rostro del ídolo al interior del templo. El cuerpo, después, era despeñado por las escalinatas.

Bolaño juega con esta idea, exacerbada desde el punto de vista colonialista para justificar la evangelización, y en "La parte de los crímenes" de 2666 pone en boca del oficial Epifanio Galindo la receta del popular "pozole”, una de las más reconocidas muestras gastronómicas mexicanas consistente en una sopa de granos de maíz, verduras, sal y, por supuesto carne:

¿Sabes de dónde viene el pozole, Lalito?, dijo. No, ni idea, dijo Lalo Cura. No es una comida del norte sino del centro del país. Es un plato típico del DF. Lo inventaron los aztecas, dijo. ¿Los aztecas?, pues está rico, dijo Lalo Cura [...]. Pues este pozole en realidad no es como el pozole original de los aztecas, dijo Epifanio. Le falta un ingrediente. ¿Y cuál es ese ingrediente?, dijo Lalo Cura. Carne humana, dijo Epifanio. No la amoles, dijo Lalo Cura" (2666 591-592).

4 Encontrar el libro de Guevara y Basoazábal en México (cuya versión más directa es una reproducción que el Gobierno de Guanajuato realizó en 1982 del manuscrito original, en sepia, a propósito del 150 aniversario de la universidad de esa ciudad) resulta una hazaña laboriosa. Son pocas las copias que se conservan y casi todas están bajo el celoso resguardo de los centinelas patrimoniales. Sin embargo, una vez que se obtiene y se hojea, el que más llama la atención de todos sus "entretenimientos" es el undécimo, titulado "Diálogo entre un Tolemáico, un Copernicano, un Abogado y un Canónigo en que se explican y aclaran más las cosas pertenecientes al sistema Copernicano" en donde, deliberadamente, el jesuita banaliza el discurso de los estudios astronómicos. Se reproduce aquí, no sin cierta dificultad debido a la ilegibilidad del manuscrito, una de las intervenciones del Abogado: "Aquí no pudo contenerse el Abogado que sobrevino ála conversación delos dos antagonistas, y sacando con grande enojo un tomo en $8^{\circ}$ dio con él un gran golpe en la mesa diciendo: ¿Nolo habia yo dicho yá que los discipulos de Copernico estan tan discordes entresí principalmente en orden álas dimensiones de un hombre que quiera seguir su sistema no sabe que medidas adoptar? Si los sistemas de Astronomia fueran religiones entre las quales se debiese escoger una, por que sin la eleccion de una de ellas se caería en el atheismo: yo confieso que no sabria qual escoger, pues en ninguno encuentro aquella luz dela verdad convincente" (43). 
En su estudio sobre los sacrificios humanos en el mundo azteca, Rodríguez Shadow recopila una serie de explicaciones de investigadores locales y extranjeros acerca del fenómeno, donde algunos proponen que "las ceremonias sacrificiales y la ingestión ritual de carne humana estaba motivada por el deseo de preservar la vida de los dioses que reproducían el universo" (El estado azteca 180), mientras que otros indican que "la occisión ritual fue usada, a veces, como un castigo, como una manera efectiva de inducir el terror entre los pueblos enemigos y desalentar toda iniciativa de ataque o rebelión" (181). Ya sea como mecanismo del terror de Estado o bien como rito religioso de preservación del orden cósmico, en ambos casos lo que se apunta es el arrebatamiento o consumación del tiempo para los sacrificados: es otro quien decide cuándo la vida acaba; es otro, una entidad superior natural o supranatural la que impone esa estructura de tiempo. Por tanto, otra vez se deriva hacia la reflexión de que el concepto de tiempo es un sistema impuesto, incluso como una amenaza para los individuos. Siguiendo a Rodríguez Shadow, el festín de esos “aztecas sangrientos" que repulsan a Ingeborg, "muestra el anhelo del gobierno de exhibir la saña que desplegaría contra sus opositores, de mostrar el sitio al que irían a parar los protagonistas de las rebeliones y el desenlace de todo intento de insubordinación" (183).

El tiempo es una posibilidad, pero a su vez un totalitarismo. El universo como la "primera edición" del gran grimorio donde comprender los avatares del tiempo puede explicarse desde Borges o Galileo, desde Hawking o los aztecas, pero en todas esas reflexiones parece manifestarse una historia latente, que se hace manifiesta por Archimboldi: la escritura de un libro de saber es por lo general antropofágica, otra forma de decir que el saber implica sacrificios humanos. En ese sentido, Archimboldi estaría prodigando un mensaje siniestro: la creación literaria y su posterior estudio conducirán a su sobrino, a su hermana, a los críticos de su obra y a él mismo, en el final de la novela, al altar de sacrificio anunciado desde el epígrafe mismo de Charles Baudelaire ("Un oasis de horror en medio de un desierto de aburimiento"), pues todos convergen allí donde está el mal: la ciudad Santa Teresa.

\section{Archimboldi, lector de Ansky}

Se ha tratado de mostrar cómo los distintos personajes que traban contacto con Hans Reiter (la baronesa von Joachimsthaler, el director de orquesta, Hugo Halder, Noburo Nisamata, Ingeborg, etcétera) parecen tener una disposición distinta y desestimar cualquier prejuicio en torno a la percepción del tiempo. Pero, ¿cuál es la visión de propio Reiter?, ¿ de dónde surge su particular trasposición de las estructuras temporales?

Una vez terminada su participación en el ejército alemán, el futuro escritor se empleará como vigilante de un bar. Aunque permanece atento al destino editorial de sus manuscritos (que son sistemáticamente rechazados o bien aceptados con cláusulas hilarantes por pequeñas editoriales de Alemania), se da cuenta de golpe que padece de 
sequía literaria. El descubrimiento traerá aparejada una distorsión temporal, demostrando otra vez que debido a la cercanía con el fenómeno artístico, toda circunstancia pierde volumen o acaba por sumergirse en un territorio espacio-temporal diverso. El siguiente párrafo se encuentra funcionalmente entre dos situaciones que impulsarán a Hans Reiter a llevar el resto de su existencia como Benno von Archimboldi: el envío a una editorial en Münich del manuscrito rechazado por Bittner y la aceptación, por parte del señor Bubis, de su primera novela, Lüdicke:

Esa noche, mientras trabajaba en la puerta del bar, se entretuvo en pensar en un tiempo de dos velocidades, uno era muy lento y las personas y los objetos se movían en este tiempo de forma casi imperceptible, el otro era muy rápido y todo, hasta las cosas inertes, centelleaban de velocidad. El primero se llamaba Paraíso, el segundo Infierno, y lo único que deseaba Archimboldi era no vivir jamás en ninguno de los dos (2666 1001-1002).

El Paraíso (donde los acontecimientos transcurren cansinamente y el entorno parece fijado en el orden) y el Infierno (donde se descubre que lo inerte es, en realidad, estacionario y donde el entorno tiende hacia el desorden) serán los espacios en los que transcurren la vida y obra de Reiter como Archimboldi. Dos tiempos en un espacio (uno ordenado y el otro caótico) supone volver a pensar en que se ha educado la conciencia para seguir los avatares de una sola de las versiones del universo, ignorando los universos paralelos donde los acontecimientos son análogos y las virtualidades se actualizan en pos de otros objetivos.

Esa percepción de al menos dos tiempos habitando un mismo espacio será decodificada satisfactoriamente cuando Archimboldi se enliste como soldado de la división 79 en el frente ruso, durante la Segunda Guerra Mundial, y descubra allí una lectura casi epifánica. En su juventud, enrolado como soldado de división, Hans Reiter recibe una bala en la garganta. Luego de ser operado, se le otorga la cruz de hierro en el hospital de campaña de Novoselivske. Mientras espera su traslado a Alemania o bien su regreso al frente, es enviado con otros tres heridos de su división a la aldea de Kostekino, a orillas del río Dniéper (como se recordará, el escenario de una de las mayores batallas durante la guerra). Allí, Reiter se instala en una isba vacía. En su interior, realiza un hallazgo que será definitivo para su destino como futuro escritor: las anotaciones de un tal Borís Abramovich Ansky. Los papeles de Ansky resultan ser el registro de sus años de formación como hombre, como soldado y como artista. La fascinación de Ansky por el pintor italiano Giuseppe Arcimboldo le proporcionará a Reiter el esquema general de su temática como escritor. De esta manera, Reiter pasa sus días rusos en compañía del manuscrito, complaciéndose con las reflexiones de Ansky cuando este observa atentamente el fenómeno aquí estudiado:

En una de sus últimas anotaciones menciona del desorden el universo y dice que sólo en ese desorden somos concebibles. En otra, se pregunta qué quedará cuando el universo muera y el tiempo y el espacio mueran con él. Cero, nada. 
Esta idea, sin embargo, le da risa. Detrás de toda respuesta se esconde una pregunta, recuerda Ansky que dicen los campesinos de Kostekino. Detrás de toda respuesta inapelable se esconde una pregunta aún más compleja. La complejidad, no obstante, le da risa y a veces su madre lo oye reírse en la buhardilla, como cuando tenía diez años. Ansky piensa en los universos paralelos. Por aquellos días Hitler invade Polonia y empieza la Segunda Guerra Mundial. Caída de Varsovia, caída de París, ataque a la Unión Soviética. Sólo en el desorden somos concebibles. Una noche Ansky sueña que el cielo es un gran océano de sangre. En la última página del cuaderno traza una ruta para unirse a los guerrilleros (920).

Como en Amberes, en "La parte de Archimboldi" existe una virtualidad primigenia donde puede desarrollarse una multiplicidad de historias, el camino de la uni-versalidad (es decir, la elección de una sola de esas versiones de los hechos) que tome esa virtualidad implica necesariamente la organización de los acontecimientos de manera crono-lógica. Las demás historias posibles quedan en algún espacio, con mayor o menor desarrollo y con otro tipo de temporalidad. Por eso Bolaño narra (y se asume que Archimboldi es el mejor lector de toda esa narración) que inmediatamente después de que Ansky piense en los "universos paralelos", Hitler invade Polonia como actualización de esa virtualidad que sólo se había, hasta entonces, tomado como amenaza. La invasión a Varsovia, a París y la posterior guerra en suelo soviético son sólo una partición de "significantes" para organizar el caos. La Segunda Guerra Mundial es reflejada en la novela, entonces, como el evento donde en el mundo material de la "realidad", el caos temporal se manifestó de manera evidente. Un dato no menos importante: en ese evento, las "fronteras" (geográficas) también se relativizaron. Ansky es testigo, luego, de un tercer suceso: un sueño, una dramatización onírica donde el cielo (el lugar donde todo empezó y donde todo acabará) se desangra.

Ansky no sólo le otorgará a Archimboldi la particularidad de un seudónimo, sino una cosmovisión distinta para su posterior programa literario y su propio derrotero como personaje. Tanto así, que padece la ruptura de sus coordenadas espaciotemporales "reales" a partir de la presencia de un "universo paralelo", un mundo posible que no tiene ubicación reconocible para la linealidad cronológica: "Hacer el amor sí que lo hacía", narra Bolaño en un periodo de crisis de Archimboldi, "aunque, en ocasiones, en mitad del acto, se iba a otro planeta, un planeta nevado en donde él memorizaba el cuaderno de Ansky" (996).

La percepción de Reiter (y la posterior plasmación en sus escritos) del fenómeno anacrónico del tiempo estará condicionada por la lectura del anteriormente citado pasaje de Ansky. La literatura, debido a su condición de "universo paralelo", será ese espacio en donde el sujeto podrá "concebirse" alternativamente. Archimboldi entiende pronto que la literatura pertenece al mismo orden de cosas que los sueños, en tanto revelación de información trascendente para el que escribe, pero también para ese que lee y que posteriormente escribirá. Asumiendo los riesgos, la obra de 
Archimboldi es una invitación a entrar en ese "agujero negro" donde el tiempo se vuelve estacionario. Por eso quienes se acercan a esa obra recalan sin miramientos en Santa Teresa: "Cuando Archimboldi dejó a su hermana se marchó a Hamburgo, donde pensaba coger un vuelo directo a México" (1117). Archimboldi es el mejor dotado para revelar ese secreto, pero aquel propósito queda trunco igual que la novela de Bolaño, abierta hacia las múltiples respuestas que pueda tener la interrogante del movimiento final del escritor alemán hacia México.

Si en el final de Los detectives salvajes la búsqueda de Cesárea Tinajero, quien también es capaz de torcer la realidad ${ }^{5}$, finaliza con uno de sus posibles propósitos (el sacrificio, la martirización de la líder espiritual), puede especularse que el final de 2666 postula el movimiento inverso: el buscado irá al encuentro de sus buscadores, con la esperanza de que, uniéndose a las demás piezas del rompecabezas ya instaladas en el tablero de Santa Teresa (Klaus Haas, Norton, Amalfitano, Fate, Pelletier, Espinoza, todo como en un cuadro de Arcimboldo), exista algún fin del tiempo.

\section{Referencias}

Bolaño, Roberto. Amuleto. Barcelona: Anagrama, 1999. Medio impreso

---. Putas asesinas. Barcelona: Anagrama, 2001. Medio impreso

---. 2666. Barcelona: Anagrama, 2004. Medio impreso

---. Los detectives salvajes. Barcelona: Compactos Anagrama, 2005. Medio

impreso.

---. El secreto del mal. Barcelona: Anagrama, 2007. Medio impreso

---.El Tercer Reich. Barcelona: Anagrama, 2010. Medio impreso

Borges, Jorge Luis. Ficciones. Buenos Aires: Emecé, 1999. Medio impreso.

Elmore, Peter. "2666: La autoría en el tiempo del límite”. Bolaño salvaje. Comps.

Edmundo Paz Soldán, Gustavo Faverón Patriau. Barcelona: Candaya, 2008. 259-293. Medio impreso.

Guevara y Basoazábal, Andrés de. Pasatiempos de cosmología o entretenimientos familiares acerca de la disposición del universo [facsímile]. Guanajuato: Gobierno del Estado de Guanajuato-Universidad de Guanajuato, 1982. Medio impreso. Hawking, Stephen W. Historia del tiempo. Del big bang a los agujeros negros. Trad. Miguel Ortuño. Barcelona: Crítica, 1988. Medio impreso.

Manzi, Joaquín. "El secreto de la vida (no está en los libros)”. Roberto Bolaño. La es-

5 "No era que el cuarto estuviera desordenado o que oliera mal (como preguntó Belano) o que su pobreza hubiera traspasado los límites de la pobreza decente o que la suciedad de la calle Rubén Darío tuviera su correlato en cada uno de los rincones de la habitación de Cesárea, sino algo más sutil, como si la realidad, en el interior de aquel cuarto perdido, estuviera torcida, o peor aún, como si alguien, Cesárea, ¿quién si no?, hubiera ladeado la realidad imperceptiblemente, con el lento paso de los días. E incluso había una opción peor: que Cesárea hubiera torcido la realidad conscientemente" (Los detectives salvajes 595). 
critura como tauromaquia. Comp. Celina Manzoni. Buenos Aires: Corregidor, 2002. 153-165. Medio impreso.

Poblete Alday, Patricia. Roberto Bolaño: Otra vuelta de tuerca. Santiago: Universidad Academia de Humanismo Cristiano, 2010. Medio impreso.

Ríos Baeza, Felipe A. “Arturo Belano: el viajero en el tiempo”. Roberto Bolaño: Ruptura y violencia en la literatura finisecular. Ed. Felipe A. Ríos Baeza. México: Eón, 2010. 219-252. Medio impreso.

---. "Las jornadas del caos: La noción de tiempo en Los detectives salvajes, de Roberto Bolaño". Revista Iberoamericana. Universidad Nacional de Seúl (Vol. 23, №3, diciembre de 2012). 57-79. Medio impreso.

Rodríguez Shadow, María. El estado azteca. México: Universidad Autónoma del Estado de México, 1990. Medio impreso.

Slöterdijk, Peter. Esferas I. Trad. Isidoro Reguera. Madrid: Siruela, 2003. Medio impreso. Vásquez Rocca, Adolfo. "Música y filosofía. Registros polifónicos: de Johnny Cage a Peter Sloterdijk». Revista Encuentros Multidisciplinarios No 24, SeptiembreDiciembre (2006). Madrid: Universidad Autónoma de Madrid. Sitio web. Fecha de ingreso: 13 de agosto de 2013. Medio impreso.

Recibido: 15 agosto 2014 Aceptado: 02 noviembre 2014 